\title{
Erratum to: Holocene History of Arctic Ice Shelves
}

\author{
John H. England, David J.A. Evans, and Thomas R. Lakeman
}

\section{Erratum to:}

Chapter 7 in: L. Copland, D. Mueller (eds.), Arctic Ice Shelves and Ice Islands, Springer Polar Sciences, DOI 10.1007/978-94-024-1101-0_7.

The original version of this chapter was inadvertently published with incorrect name of the author (David A. Evans). The correct name should be David J. A. Evans.

The incorrect order of reference list was published in the original version of this chapter. It should be organized alphabetically. 